\title{
A novel Alu-based real-time PCR method for the quantitative detection of plasma circulating cell-free DNA: Sensitivity and specificity for the diagnosis of myocardial infarction
}

\author{
XIAOLI LOU ${ }^{1}$, YANQIANG HOU ${ }^{1}$, DONGYU LIANG ${ }^{1}$, LIANG PENG ${ }^{1}$, \\ HONGWEI CHEN $^{1}$, SHANYUAN MA ${ }^{1}$ and LURONG ZHANG ${ }^{2}$
}

\author{
${ }^{1}$ Department of Central Laboratory, Songjiang Hospital Affiliated First People's Hospital, \\ Shanghai Jiao Tong University, Shanghai 201600, P.R. China; ${ }^{2}$ Department of Radiation Oncology, \\ Shands Cancer Center, University of Florida, Gainesville, FL 32610, USA
}

Received June 17,2014; Accepted October 20, 2014

DOI: $10.3892 / \mathrm{ijmm} .2014 .1991$

\begin{abstract}
In the present study, we aimed to develop and validate a rapid and sensitive, Alu-based real-time PCR method for the detection of circulating cell-free DNA (cfDNA). This method targeted repetitive elements of the Alu reduplicative elements in the human genome, followed by signal amplification using fluorescence quantification. Standard Alu-puc57 vectors were constructed and 5 pairs of specific primers were designed. Valuation was conducted concerning linearity, variation and recovery. We found 5 linear responses $\left(\mathrm{R}_{1-5}=0.998-0.999\right)$. The average intra- and inter-assay coefficients of variance were 12.98 and $10.75 \%$, respectively. The recovery was $82.33-114.01 \%$, with a mean recovery index of $101.26 \%$. This Alu-based assay was reliable, accurate and sensitive for the quantitative detection of cfDNA. Plasma from normal controls and patients with myocardial infarction (MI) were analyzed, and the baseline levels of cfDNA were higher in the MI group. The area under the receiver operating characteristic (ROC) curve for Alu1, Alu2, Alu3, Alu4, Alu5 and Alu (Alu1 + Alu 2 + Alu3 + Alu 4 Alu5) was 0.887, 0.758, 0.857, 0.940, 0.968 and 0.933 , respectively. The optimal cut-off value for Alu1, Alu2, Alu3, Alu4, Alu5 and Alu to predict MI was 3.71, 1.93, $0.22,3.73,6.13$ and $6.40 \mathrm{log}$ copies $/ \mathrm{ml}$. We demonstrate that this new method is a reliable, accurate and sensitive method for the quantitative detection of cfDNA and that it is useful for studying the regulation of cfDNA in certain pathological conditions. Alu4, Alu5 and Alu showed better sensitivity and specificity for the diagnosis of MI compared with cardiac troponin I (cTnI), creatine kinase MB (CK-MB) isoenzyme and
\end{abstract}

Correspondence to: Dr Yanqiang Hou, Department of Central Laboratory, Songjiang Hospital Affiliated First People's Hospital, Shanghai Jiao Tong University, 748 Middle Zhongshan Road, Songjiang, Shanghai 201600, P.R. China

E-mail: houyanqiang@aliyun.com

Key words: cell-free DNA, Alu, real-time PCR, myocardial infarction lactate dehydrogenase (LDH). Alu5 had the best prognostic ability.

\section{Introduction}

Circulating cell-free DNA (cfDNA) mainly originates from programmed cell death or acute cellular injury and reflects the extent of cellular damage. cfDNA can be determined in the serum or plasma from healthy individuals at low concentrations, ranging from 2.5 to $27.0 \mathrm{ng} / \mathrm{ml}$ (1). High concentrations of cfDNA have been widely described in a variety of clinicopathological conditions, such as malignancies, trauma, infection, pregnancy-associated disorders and autoimmune diseases (2-5). It has been reported that the levels of cfDNA in serum and plasma are significantly increased in patients with colorectal, ovarian and testicular cancer (6-8).

Alu repeats, 300 nucleotides long with a copy number of approximately $1.4 \times 10^{6}$ per genome, are short interspersed elements (SINEs) and are the most abundant sequences in the human genome. Alu sequences account for $>10 \%$ of the genome and are abundant in blood (9-11). Therefore, Alu-based real-time PCR is a potentially sensitive approach for the measurement of human cfDNA in blood. In the present study, we designed 5 different sizes of Alu primers $(201,170,147$, 113 and $76 \mathrm{bp}$ ) and used real-time PCR for the measurement of cfDNA. We aimed to determine whether Alu-based real-time PCR can serve as an effective tool for the detection of cfDNA.

Myocardial infarction (MI) is the end result of coronary artery disease and a condition associated with the apoptosis and death of cardiomyocytes. cfDNA is mainly released following programmed cell death or acute cellular injury; therefore, we detected the cfDNA in plasma from patients with MI plasma using Alu-based real-time PCR.

\section{Materials and methods}

Standard Alu-puc57 vector construction and verification. Alu-puc57 vectors were constructed by cloning the entire Alu sequence amplified by PCR into the puc57 vector (Sangon Biotech Co., Ltd., Shanghai, China) at the EcoRI and HindIII 
restriction sites. The Alu sequence was amplified using a forward primer with an EcoRI restriction site (5'-gaa ttc aga cca tcc tgg cta aca cg-3') and a reverse primer with a HindIII restriction site (5'-aag ctt aga cgg agt ctc gct ctg tc-3'). PCR was performed at $95^{\circ} \mathrm{C}$ for $2 \mathrm{~min}, 94^{\circ} \mathrm{C}$ for $20 \mathrm{sec}, 55^{\circ} \mathrm{C}$ for $30 \mathrm{sec}$, and $72^{\circ} \mathrm{C}$ for $30 \mathrm{sec}$, repeated for 35 cycles. Extension was performed at $72^{\circ} \mathrm{C}$ for $10 \mathrm{~min}$ and $4^{\circ} \mathrm{C}$ for $10 \mathrm{~min}$. The reconstructed plasmid, Alu-puc57, was verified by PCR sequencing.

Sample preparation and clinical information. We examined 120 patients diagnosed with MI (40-80 years of age; 60 males and 60 females) at the Songjiang Hospital Affiliated to the First People's Hospital, Shanghai Jiao Tong University, Shanghai, China. Peripheral blood samples were collected within $6 \mathrm{~h}$ of admission after the onset of chest pain. The patients had been diagnosed with MI on the basis of clinical symptoms, 12-lead electrocardiography and positive cardiac biomarkers. A twosite immunoenzymometric assay was used to test for cardiac troponin I (cTnI), creatine kinase (CK) MB (CK-MB) isoenzyme, myoglobin (MYO) and lactate dehydrogenase (LDH) with the Cobas c501 System analyzer (Hoffmann-La Roche, Basel, Switzerland). Blood samples were collected from 60 healthy control subjects (40-80 years of age; 30 males and 30 females). These individuals had no history of autoimmune disease, tissue injury, or trauma at the time of examination and their hematological-biochemical profile was normal. All samples were anonymous and the Ethics Committee of the Shanghai Songjiang District Central Hospital approved this study. Participants provided their written informed consent to participate in this study and the ethics committees approved this consent procedure. Fresh blood was collected into tubes containing clot activation additive for serum and into tubes containing EDTA for plasma (Shanghai Kehua Bio-Engineering Co., Ltd., Shanghai, China). Whole blood was separated at $4^{\circ} \mathrm{C}$ by centrifugation at $1,600 \mathrm{x}$ for $10 \mathrm{~min}$. Plasma samples were stored at $-80^{\circ} \mathrm{C}$. After collection, all samples were analyzed for cfDNA on the same day in order to minimize testing error.

Primer design. Five primer pairs amplifying different fragments of Alu were designed to quantify the amount of cfDNA and to characterize the fragmentation pattern. The Alu1, Alu2, Alu3, Alu4 and Alu5 sequences are shown in Table I. The sequences of Alu and the primer model are shown in Fig. 1. The products of the 5 primers were 201, 170, 147, 113 and $76 \mathrm{bp}$, respectively.

Detection of cfDNA in plasma by real-time PCR. Real-time PCR was performed in triplicate on an ABI 7500 (Applied Biosystems, Foster City, CA, USA). Each $50 \mu$ l PCR reaction consisted of $25 \mu \mathrm{l}$ SYBR-Green mix (Takara Bio, Dalian, China), $2 \mu \mathrm{l}$ forward/reverse primer $(10 \mu \mathrm{M})$ and $5 \mu \mathrm{l}$ plasma sample. The cycling conditions were $90^{\circ} \mathrm{C}$ for $30 \mathrm{sec}$, followed by 40 cycles at $95^{\circ} \mathrm{C}$ for $5 \mathrm{sec}$ and $60^{\circ} \mathrm{C}$ for $34 \mathrm{sec}$. The specificity of the PCR products was confirmed by melting curve analysis. The running time required $33 \mathrm{~min}$ for the cfDNA assay. Each run included water blanks and serial dilutions of an external standard, Alu-puc57 vector. The resultant copies of different primers were calculated into log values. The copies of Alu1, Alu2, Alu3, Alu4 and Alu5 were added and calculated by logarithmic conversion and recorded as Alu addition.
Table I. Primers of Alu sequences.

\begin{tabular}{llll}
\hline $\begin{array}{l}\text { Primer } \\
\text { name }\end{array}$ & \multicolumn{1}{c}{ Sequence } & $\begin{array}{l}\text { Tm } \\
\left({ }^{\circ} \mathrm{C}\right)\end{array}$ & $\begin{array}{l}\text { Size } \\
(\mathrm{bp})\end{array}$ \\
\hline S1 & aga cca tcc tgg cta aca cg & 56.8 & 200 \\
A1 & aga cgg agt ctc gct ctg tc & 57.2 & \\
S2 & cta aca cgg tga aac ccc g & 56.0 & 170 \\
A2 & cgc cca ggc tgg agt g & 59.4 & \\
S3 & gtg aaa ccc cgt ctc tac taa aaa & 54.7 & 147 \\
A3 & gag tgc agt ggc gcg at & 58.8 & \\
S4 & tac aaa aaa tta gcc ggg cg & 55.6 & 113 \\
A4 & gat ctc ggc tca ctg caa g & 55.8 & \\
S5 & aaa att agc cgg gcg tg & 53.4 & 76 \\
A5 & gtt cac gcc att ctc ctg c & 56.6 & \\
\hline
\end{tabular}

Tm, temperature.

Linearity, lower limit of detection and variation in the Alu-based real-time PCR. The samples used for the evaluation of the method were dilutions of the standard Alu-puc57 vector with the original content of $1 \times 10^{10}$ copies $/ \mathrm{ml}$. The linearity of cfDNA quantification was assessed using serial dilutions $1 \times 10^{6}, 1 \times 10^{7}, 1 \times 10^{8}, 1 \times 10^{9}$ and $1 \times 10^{10}$ copies $/ \mathrm{ml}$ of the standard Alu-puc57 vector. The samples were tested in triplicate in 3 different runs. The dilution concentrations for the variation analysis were $4 \times 10^{6}, 8 \times 10^{7}$ and $2 \times 10^{9}$ copies $/ \mathrm{ml}$. The intra-sample reproducibility of Alu-based real-time PCR was evaluated with samples tested 13 times in the same batch. The inter-sample reproducibility was evaluated with samples tested in each run for 20 consecutive days.

The lower limit of detection was used to demonstrate the sensitivity of detection of Alu-based real-time PCR, which was defined as the mean \pm 2 SDs of 0 copies/ml cfDNA.

$D N A$ recovery by real-time $P C R$. The reliability of Alu-based real-time PCR was examined by measuring the recovery of different Alu sequences from spiked plasma samples. The DNA concentrations in each of 2 randomly selected standard samples were first measured by real-time PCR. Analytical recovery was evaluated by the addition of $0.1 \mathrm{ml}$ of the calibrator at concentrations of $1.2 \times 10^{7}$ or $1 \times 10^{10}$ copies $/ \mathrm{ml}$ to $0.9 \mathrm{ml}$ of $4 \times 10^{6}$ or $2 \times 10^{9}$ copies $/ \mathrm{ml}$ sample, respectively. Five microliters of each mixture were subsequently loaded into separate detection wells in triplicate for DNA quantification by real-time PCR. Recovery was calculated using the following equation:

$$
\text { Recovery }=\frac{\text { Measurement by real-time PCR }}{\text { Baseline }+ \text { spiked }} \times 100
$$

where recovery is the total amount of DNA measured by real-time PCR in the spiked sample (measured by real-time PCR), over the sum (expected) of the DNA quantity in samples before spiking (baseline) and the amount of DNA spiked (spiked), expressed as a percentage. 


\section{agaccatcctggctaacacggtgaaaccccgtctctactaaaaatacaaaaaattagccgggcgtggtg gcgggcgcctgtagtcccagctactcgggaggctgaggcaggagaatggcgtgaacccgggaggcg gagcttgcagtgagccgagatcgcgccactgcactccagcctgggcgacagagcgagactccgtct}

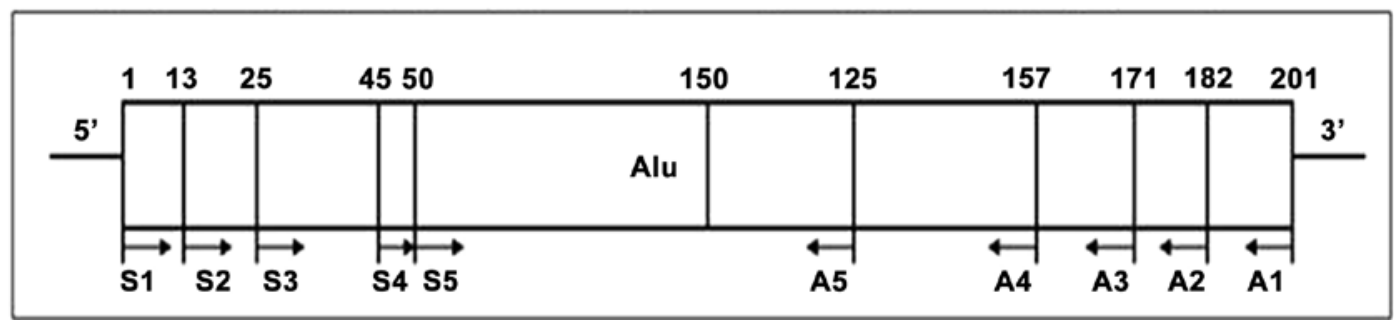

Figure 1. Sequence of Alu and scheme for amplification. PCR primers are shown as lines with arrowheads to indicate $5^{\prime} \rightarrow 3^{\prime}$ orientation relative to the Alu sequence. The sequences of each primer are shown in Table I.

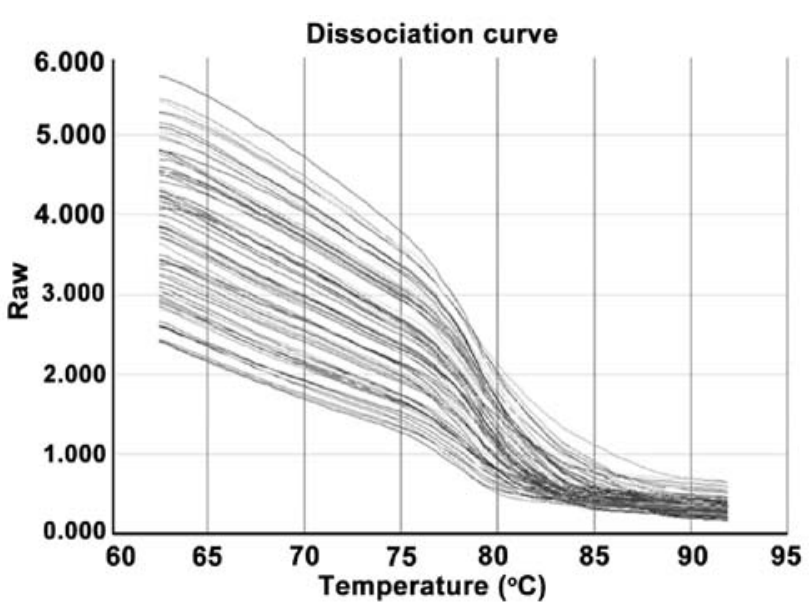

Figure 2. Melting curve of amplification from each of the standard dilutions and plasma samples.

Statistical analysis. Quantitative data are expressed as the means \pm SD. Statistical analysis was carried out using SPSS software for Windows version 13.0. Where appropriate, ANOVA was first used to ascertain whether there was a significant difference between the means. In order to evaluate the predictive value of Alu-based real-time PCR, receiver operating characteristic (ROC) curve analysis was applied and the area under the curve (AUC) was compared. All statistical tests were two-sided, and the significance level was set at $\mathrm{p}<0.05$.

\section{Results}

Verification of Alu-p57 vector and development of real-time $P C R$. The reconstructed plasmid Alu-puc57 was verified by PCR sequencing which confirmed the accurate bases (data not shown). Five pairs of primers that framed the human Alu sequence were selected and constructed to detect quantitative changes in cfDNA in human peripheral blood (Fig. 1). It was possible to amplify 5 DNA sequences of Alu. The primers are shown in Table I. Correspondingly, the products generated by real-time PCR exhibited a range of sizes at 201, 170, 147, 113 and $76 \mathrm{bp}$. When the different standard dilutions and plasma samples were melted during the amplification process, a sharp composite melting curve was obtained (Fig. 2). As each of the

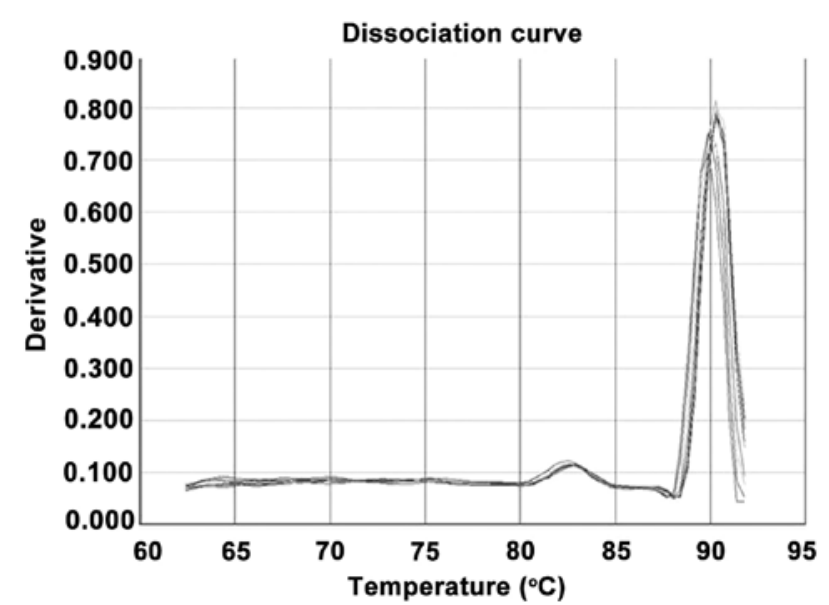

Figure 3. Melting peak transformed from the melting curve.

reactions was heated toward the denaturation temperature, the fluorescence levels decreased to background levels within a $7^{\circ} \mathrm{C}$ range between 80 and $87^{\circ} \mathrm{C}$. Following background subtraction, the derivative of the curve was used to convert the melting curves to a melting peak (Fig. 3). Multiple single peaks occurring in a narrow range of melting temperature indicate that the method was target specific.

Linearity. We performed experiments using several 4-fold dilutions starting from $1 \times 10^{10}$ copies/reaction and ending at $1 \times 10^{6}$ copies/reaction, resulting in evenly spaced amplification curves (Fig. 4). The evaluation of the Alu-based real-time PCR assay, shown with serial 10-fold dilutions of the standard Alu-puc57 plasmid, found 5 linear responses $\left(R_{1}=0.998\right.$, $\mathrm{R}_{2}=0.998, \mathrm{R}_{3}=0.998, \mathrm{R}_{4}=0.998$ and $\left.\mathrm{R}_{5}=0.999\right)($ Fig. 5).

Lower limit of detection. The lower limits of Alu1, Alu2, Alu3, Alu4 and Alu5 for detection with Alu-based real-time PCR, which were defined as the means \pm 2 SD of 15 replicates, the zero standard, were 8.89, 6.98, 7.08, 10.12 and 9.56 copies $/ \mathrm{ml}$, respectively.

Variation. For analysis of the variation of the Alu-based real-time PCR assay, we used 3 concentrations $\left(2 \times 10^{4}, 4 \times 10^{5}\right.$ 


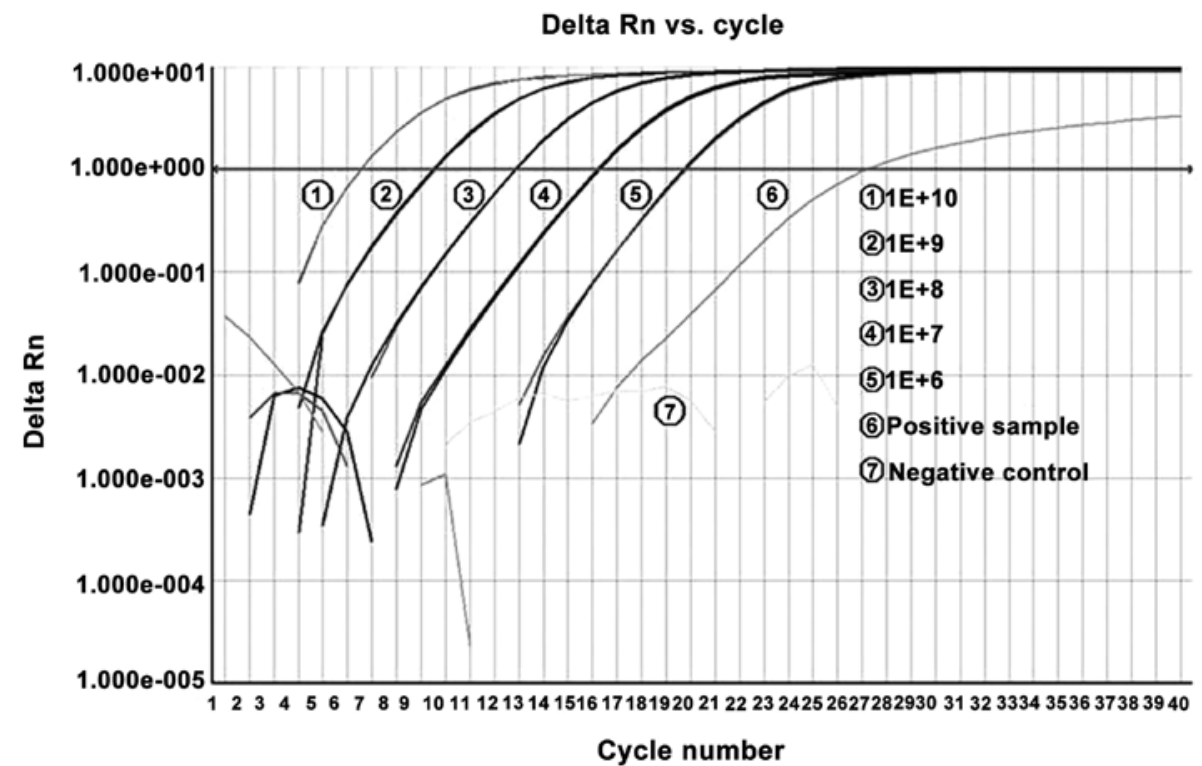

Figure 4. Amplification plots of real-time PCR for the Alu sequence. The x-axis is the cycle number of real-time PCR. The y-axis denotes the fluorescence intensity above background. Each dilution was assayed in duplicate.

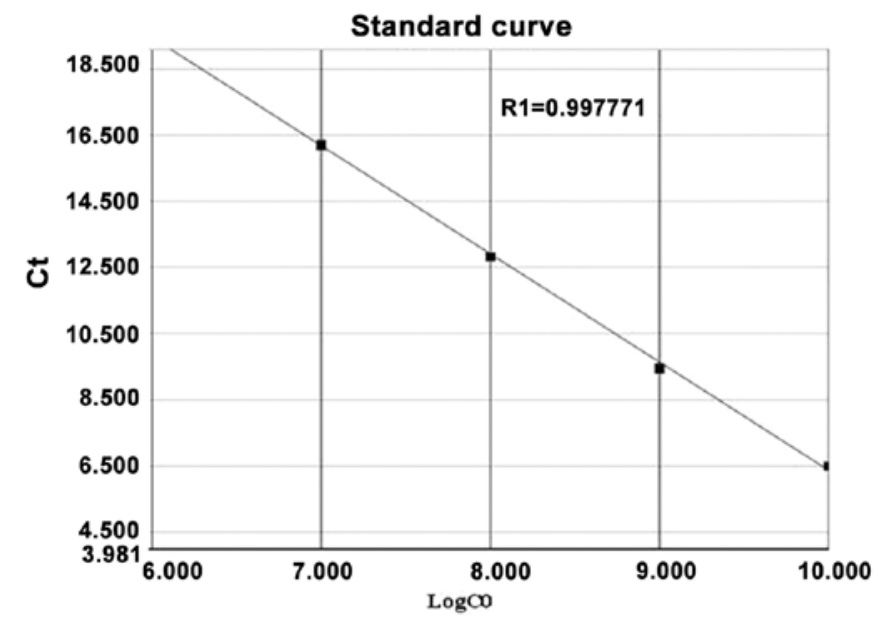

Figure 5. Linearity of Alu-based real-time PCR. The y-axis is the threshold cycle (CT) and the $\mathrm{x}$-axis denotes the log of the starting quantity of template. Each dilution was measured in duplicate. Evaluation of the linearity found 5 linear responses $\left(\mathrm{R}_{1}=0.998, \mathrm{R}_{2}=0.998, \mathrm{R}_{3}=0.998, \mathrm{R}_{4}=0.998, \mathrm{R}_{5}=0.999\right)$.

and $1 \times 10^{7}$ copies/reaction) of diluted standard Alu-puc57 plasmids. The results for within-run reproducibility are presented in Table II, obtained by assaying 13 replicates of each sample in a single assay. Similarly, the results of between-run reproducibility are presented in Table III, for each concentration measured for 20 consecutive days.

Recovery. As shown in Table IV, recovery was found to range from 82.33 to $114.01 \%$ with a mean recovery index of $101.26 \%$. The recoveries corresponding to the 2 concentrations for each primer did not differ greatly, indicating that Alu-based realtime PCR was satisfactorily reliable and consistent when used to directly estimate DNA quantity in routine plasma samples.

Analysis of cfDNA in clinical plasma samples from patients with MI and normal controls. The Alu-based real-time PCR assay was used to measure the levels of cfDNA in 120 plasma samples from patients with MI and 60 plasma samples collected from normal blood donors. The logarithmic mean value of the Alu1, Alu2, Alu3, Alu4, Alu5 and Alu cfDNA concentration was $1.75 \pm 0.24,2.92 \pm 0.44,1.72 \pm 0.32,2.85 \pm 0.12$, $3.79 \pm 0.14$ and $4.67 \pm 0.24 \log$ copies $/ \mathrm{ml}$ in the plasma samples from the normal controls. By contrast, the MI plasma samples had a high concentration of cfDNA $(4.24 \pm 0.16,5.42 \pm 0.14$, $5.08 \pm 0.25,6.99 \pm 0.24,7.21 \pm 0.17$ and $7.90 \pm 0.17 \log$ copies $/ \mathrm{ml}$ ). This indicated that the plasma samples from the patients with MI contained a higher concentration of cfDNA than the plasma samples from the normal controls (p<0.01) (Fig. 6).

Diagnostic ability of Alu based real-time PCR for the detection of MI. To evaluate the diagnostic ability of Alu-based real-time PCR for discriminating MI patients from normal controls, the ROC curves of cTnI, CK, CK-MB, LDH, Alu1, Alu2, Alu3, Alu4, Alu5 and Alu were drawn (Fig. 7). The AUC for Alu1 was 0.887 [95\% confidence interval (CI), 0.822-0.953], 0.758 (95\% CI, 0.662-0.854) for Alu2, 0.857 (95\% CI, 0.787-0.927) for Alu 3, 0.940 (95\% CI, 0.889-0.990) for Alu 4, 0.968 (95\% CI, 0.934-1.002) for Alu 5 and 0.933 (95\% CI, 0.871-0.994) for Alu (Table V). The optimal cut-off value for Alu1 to predict MI was $3.71 \log$ copies/ml (77.20\% sensitivity and 95.60\% specificity), for Alu2 1.93 log copies/ml (100\% sensitivity and $48.95 \%$ specificity), for Alu3 $0.22 \log$ copies/ $\mathrm{ml}(100 \%$ sensitivity and $60.0 \%$ specificity), for Alu4 $3.73 \log$ copies $/ \mathrm{ml}$ (86.8\% sensitivity and $95.6 \%$ specificity), for Alu5 $6.13 \mathrm{log}$ copies/ml (86.8\% sensitivity and $100 \%$ specificity) and for Alu $6.40 \mathrm{log}$ copies/ml (92.1 and $95.6 \%$ sensitivity) (Table V).

\section{Discussion}

Our study demonstrates that this Alu-based real-time PCR method is a reliable, accurate and sensitive method for the quantitative detection of plasma cfDNA in patients with MI 


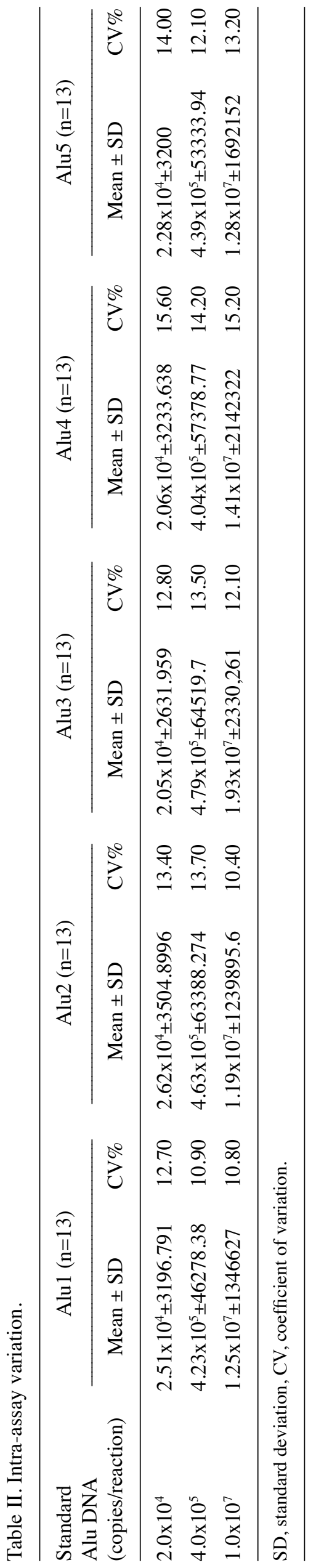

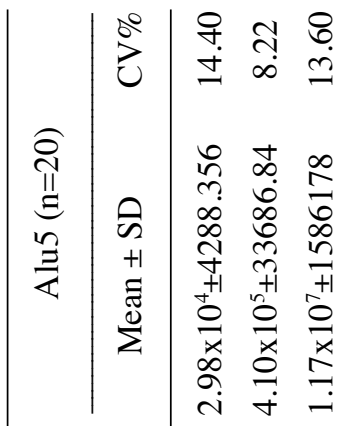

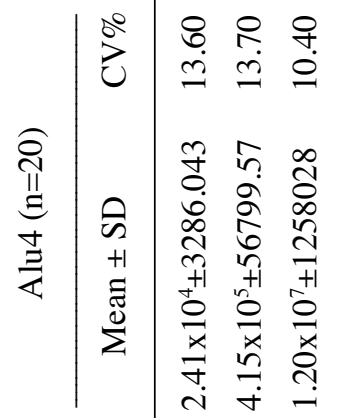

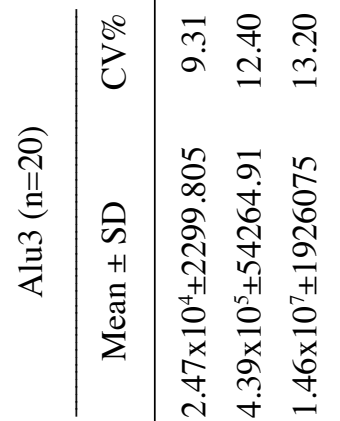

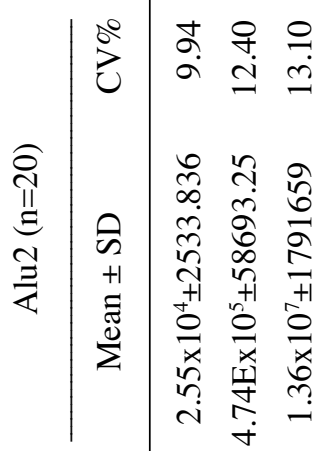

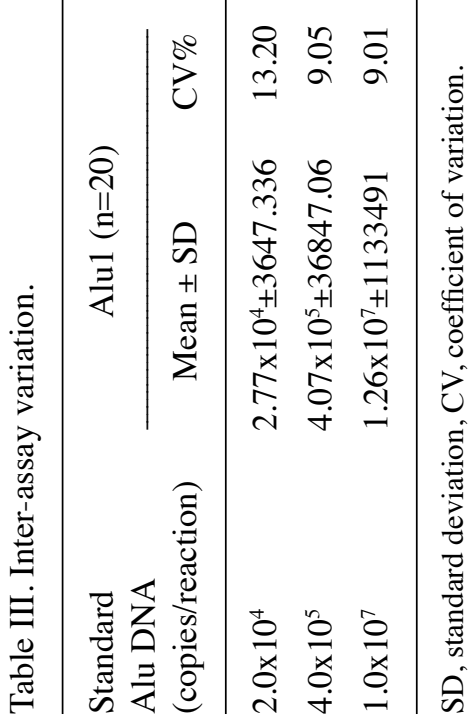


Table IV. Recovery of Alu based real-time PCR assay.

\begin{tabular}{|c|c|c|c|c|c|c|}
\hline Test set & & $\begin{array}{c}\text { Baseline } \\
\text { (copies/reaction) }\end{array}$ & $\begin{array}{c}\text { Spiked } \\
\text { (copies/reaction) }\end{array}$ & $\begin{array}{c}\text { Expected } \\
\text { (copies/reaction) }\end{array}$ & $\begin{array}{l}\text { Measured by real-time } \\
\text { PCR (copies/reaction) }\end{array}$ & $\begin{array}{l}\text { Recovery } \\
(\%)\end{array}$ \\
\hline \multirow[t]{2}{*}{ Alu1 } & Low range & $2 \times 10^{4}$ & $2 \times 10^{4}$ & $4 \times 10^{4}$ & $3.87 \times 10^{4} \pm 6360$ & $96.7 \pm 15.90$ \\
\hline & High range & $1 \times 10^{7}$ & $2 \times 10^{7}$ & $3 \times 10^{7}$ & $2.70 \times 10^{7} \pm 7688375$ & $88.90 \pm 25.62$ \\
\hline \multirow[t]{2}{*}{ Alu2 } & Low range & $2 \times 10^{4}$ & $2 \times 10^{4}$ & $4 \times 10^{4}$ & $3.90 \times 10^{4} \pm 9387$ & $98.50 \pm 23.52$ \\
\hline & High range & $1 \times 10^{7}$ & $2 \times 10^{7}$ & $3 \times 10^{7}$ & $3.40 \times 10^{7} \pm 3480102$ & $114.01 \pm 11.53$ \\
\hline \multirow[t]{2}{*}{ Alu3 } & Low range & $2 \times 10^{4}$ & $2 \times 10^{4}$ & $4 \times 10^{4}$ & $4.10 \times 10^{4} \pm 4372$ & $103.33 \pm 10.93$ \\
\hline & High range & $1 \times 10^{7}$ & $2 \times 10^{7}$ & $3 \times 10^{7}$ & $2.90 \times 10^{7} \pm 2728451$ & $99.00 \pm 9.19$ \\
\hline \multirow[t]{2}{*}{ Alu4 } & Low range & $2 \times 10^{4}$ & $2 \times 10^{4}$ & $4 \times 10^{4}$ & $3.80 \times 10^{4} \pm 4910$ & $96.80 \pm 12.38$ \\
\hline & High range & $1 \times 10^{7}$ & $2 \times 10^{7}$ & $3 \times 10^{7}$ & $3.10 \times 10^{7} \pm 2645751$ & $103.56 \pm 8.91$ \\
\hline \multirow[t]{2}{*}{ Alu5 } & Low range & $2 \times 10^{4}$ & $2 \times 10^{4}$ & $4 \times 10^{4}$ & $4.10 \times 10^{4} \pm 3215$ & $102.50 \pm 8.03$ \\
\hline & High range & $1 \times 10^{7}$ & $2 \times 10^{7}$ & $3 \times 10^{7}$ & $2.40 \times 10^{7} \pm 3844188$ & $82.33 \pm 12.92$ \\
\hline
\end{tabular}

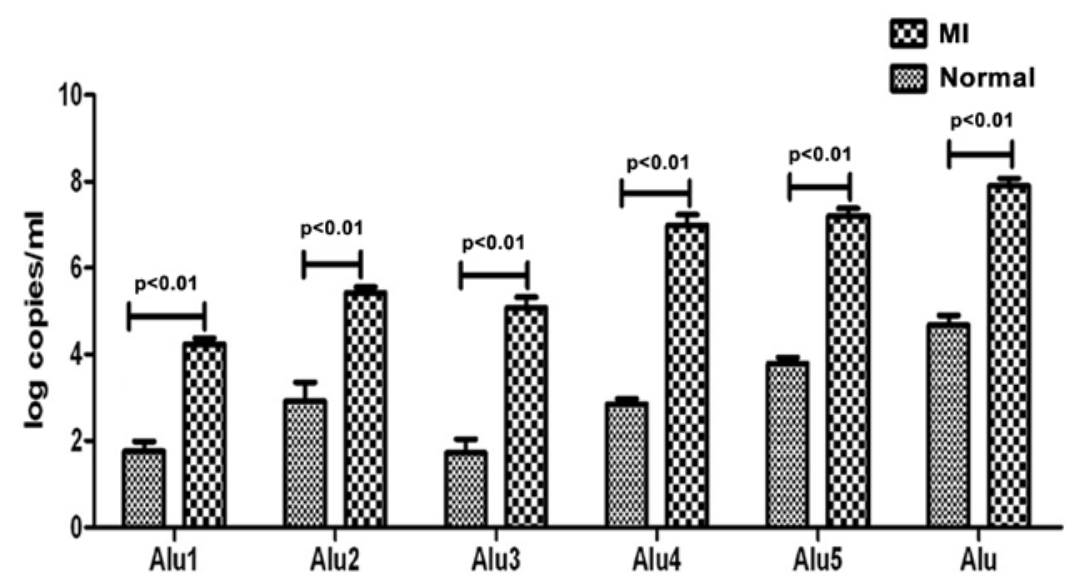

Figure 6. Analysis of cell-free DNA (cfDNA) in clinical plasma samples from normal controls and patients with myocardial infarction (MI). Patient plasma samples contained a higher concentration of cfDNA than the plasma samples from the normal controls $(\mathrm{p}<0.01)$.

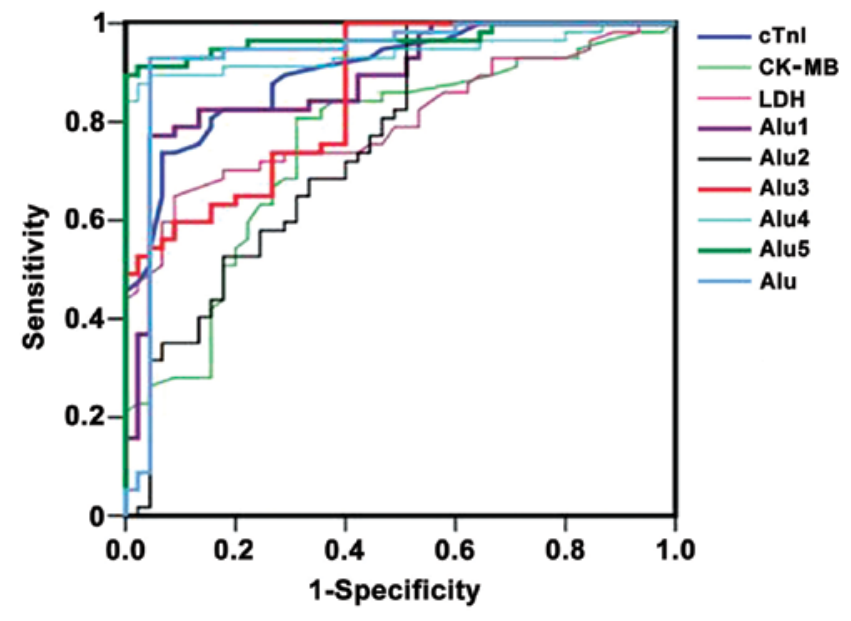

Figure 7. Receiver operating characteristic (ROC) curves of cardiac troponin I (cTnI), CK, creatine kinase MB (CK-MB) isoenzyme, lactate dehydrogenase (LDH), Alu1, Alu2, Alu3, Alu4, Alu5 and Alu. Alu4, Alu5 and Alu showed better prognostic ability for the diagnosis of myocardial infarction (MI).

for the following reasons. Firstly, we constructed the standard Alu-puc57 vectors, designed 5 specific primers based on Alu sequences, and evaluated the linearity of this real-time PCR, which showed 5 good linear responses. Secondly, the variation and recovery evaluation indicated that this Alu-based assay was an accurate method. Finally, using ROC curve analysis to determine the performance of cfDNA as a diagnostic test for MI detection, the sensitivity and specificity of Alu4, Alu5 and Alu exceeded $85 \%$, suggesting that they are adequate for MI screening, particularly Alu5.

The history of cfDNA dates back to 1948 , when it was first reported in human blood (12). Higher concentrations of cfDNA have been reported in a variety of conditions associated with cell damage or apoptosis, such as cancer (13), trauma (14), pre-eclampsia (15), certain systemic autoimmune diseases $(16)$, aging $(17,18)$, prenatal screening $(19,20)$, infection (21), leukemia (22) and sepsis (23-25). It has been reported that patients with systemic sclerosis with active disease present with significantly higher cfDNA concentrations than those with inactive disease (26). Higher cfDNA levels have been found in patients with breast cancer and systemic lupus erythematosus and rheumatoid arthritis (27-30). Increased cfDNA was reported for the first time in patients with MI that could complement troponin and CK-MB in a multiple marker test format in 2003 (31). Therefore, cfDNA levels may serve 
Table V. Prognostic ability of serum Alu for detecting cfDNA in patients with MI.

$95 \% \mathrm{CI}$

\begin{tabular}{|c|c|c|c|c|c|c|c|c|}
\hline $\begin{array}{l}\text { Test result } \\
\text { variable(s) }\end{array}$ & Area & SEM & p-value & Lower bound & Upper bound & Cut-off value & $\begin{array}{c}\text { Sensitivity } \\
(\%)\end{array}$ & $\begin{array}{c}\text { Specifity } \\
(\%)\end{array}$ \\
\hline cTnI & 0.903 & 0.029 & $\mathrm{p}<0.001$ & 0.846 & 0.959 & $1.35(\mathrm{ng} / \mathrm{ml})$ & 80.70 & 84.40 \\
\hline CK-MB & 0.752 & 0.049 & $\mathrm{p}<0.001$ & 0.655 & 0.848 & $28.50(\mathrm{IU} / \mathrm{l})$ & 80.70 & 68.90 \\
\hline LDH & 0.801 & 0.043 & $\mathrm{p}<0.001$ & 0.717 & 0.886 & 281.00 (IU/l) & 70.20 & 82.20 \\
\hline Alu1 & 0.887 & 0.033 & $\mathrm{p}<0.001$ & 0.822 & 0.953 & $3.71(\log$ copies $/ \mathrm{ml})$ & 77.20 & 95.60 \\
\hline Alu2 & 0.758 & 0.049 & $\mathrm{p}<0.001$ & 0.662 & 0.854 & $1.93(\log$ copies $/ \mathrm{ml})$ & 100.00 & 48.95 \\
\hline Alu3 & 0.857 & 0.036 & $\mathrm{p}<0.001$ & 0.787 & 0.927 & $0.22(\log$ copies $/ \mathrm{ml})$ & 100.00 & 60.00 \\
\hline Alu4 & 0.940 & 0.026 & $\mathrm{p}<0.001$ & 0.889 & 0.990 & $3.73(\log$ copies $/ \mathrm{ml})$ & 86.80 & 95.60 \\
\hline Alu5 & 0.968 & 0.017 & $\mathrm{p}<0.001$ & 0.934 & 1.002 & $6.13(\log$ copies $/ \mathrm{ml})$ & 86.80 & 100.00 \\
\hline Alu & 0.933 & 0.031 & $\mathrm{p}<0.001$ & 0.871 & 0.994 & $6.40(\log$ copies $/ \mathrm{ml})$ & 92.10 & 95.60 \\
\hline
\end{tabular}

cfDNA, cell-free DNA; MI, myocardial infarction; CI, confidence interval; SEM, standard error of the mean; cTnI, cardiac troponin I; CK-MB, creatine kinase MB isoenzyme; LDH, lactate dehydrogenase.

as a biomarker for the diagnosis and prognosis of different pathological diseases.

Alu repeats, 300 nucleotides long with a copy number of approximately $1.4 \times 10^{6}$ per genome, are SINEs and are the most abundant sequences in the human genome. Alu sequences account for $>10 \%$ of the genome and are abundant in blood (9-11). According to a high-throughput sequencing analysis performed in healthy individuals, the plasma cfDNA sequence representation mirrors that of the genome (32). Alu-based real-time PCR may be a potentially sensitive approach for the measurement of human cfDNA in blood.

In our study, we designed 5 primer pairs amplifying different fragments of Alu to quantify the amount of cfDNA and characterize the fragmentation pattern. The products of the 5 primers were 201, 170, 147, 113 and $76 \mathrm{bp}$. We set up a novel real-time PCR based on the Alu sequences. We designed 5 pairs of specific primers for different PCR products of Alu sequences. The melting curves were measured and multiple single peaks occurring in a narrow range of melting temperature indicated that the method was target-specific. Valuation was conducted concerning linearity, variation and recovery. Evaluation of the linearity found 5 linear responses. The average intra- and inter-assay coefficients of variance were 12.98 and $10.75 \%$, respectively. The recovery was found to range from 82.33 to $114.01 \%$, with a mean recovery index of $101.26 \%$. Thus, this Alu-based assay is a reliable, accurate and sensitive method for the quantitative detection cfDNA.

The traditional spectrophotometric technique for the determination of the concentration of DNA is through the measurement of absorbance at a wavelength of $260 \mathrm{~nm}$ (33). The major disadvantages of this technique are the interference caused by contaminants in the process of nucleic acid preparation. Currently, several techniques, including PCR-based assays, fluorimetric methods and hybridization methods, have been used for the detection of cfDNA. PCR-based assays, including real-time PCR (34-37), duplex real-time PCR and methylation-specific PCR (38), are the most common methods available for the detection of cfDNA (39). PCR methods are based on the use of commercial DNA extraction kits for the purification of cfDNA. The use of gene-specific primers or probe sequences requires the optimization of PCR conditions. It has been shown that DNA quantification using fluorescent dyes is a simple method that can detect nearly all DNA fragments not specific for a DNA gene (40). Sang et al developed a method for the quantification of cfDNA by capillary zone electrophoresis with laser-induced fluorescence detection (41). Jing et al described a branched DNA (bDNA) method based on SINEs (Alu repeats) for the direct quantification of cfDNA in serum/plasma (42).

The present study builds on these previous methods; however, our approach and findings differ in several important ways. Firstly, as a result of the diversity of protocols, reagents and devices preventing a meaningful comparison of data from different laboratories, there is a need for the standardization of a highly sensitive molecular biology technique for the measurement of cfDNA. We constructed a standard Alu-puc57 vector that can be used as a standard substance or as a quality control in different laboratories. Secondly, we used real-time PCR to amplify the Alu sequence, which was more cost-effective and sensitive than the bDNA assay. Thirdly, we amplified the Alu sequences, which are specific genome repeats. However, other studies evaluate fragmentation of the whole genome. Other techniques measure the released mtDNA. These techniques bring us closer to producing reliable and quantitative results.

MI is the end result of coronary artery disease and the mortality rate associated with this disease worldwide has decreased from $10.5 \%$ in 1999 to $7.8 \%$ in 2008 . The decrease is possibly explained by timely diagnosis that allows clinicians to adopt appropriate treatment (43). cTnI, CK, CK-MB and LDH have been used for the diagnosis of MI and for the follow-up of patients (44). Increased cfDNA in patients with MI may complement cTnI, CK-MB and MYO in a multiple marker format. Jing et al found that cfDNA was significantly higher in patients with MI compared to the controls (42). Chang et al found that the average concentration of cfDNA in 55 patients with MI was $>10$-fold higher than that in 274 normal controls. There was no correlation between the concentration of cfDNA and CK-MB or cTnI (31). However, 
Cui et al found a trend towards a positive association between peak plasma cfDNA and established markers of necrosis, such as CK-MB and cTnI (45). Destouni et al found that the concentration of cfDNA was significantly higher in patients with MI than that in a healthy control group using real-time PCR of the $\beta$-globin gene during hospitalization (46). The concentration of cfDNA has potential clinical value in monitoring progress and judging the prognosis of patients with MI (47). Shimony et al described a novel rapid fluorometric assay, the fluorochrome SYBR-Gold, which does not require prior processing of samples, for the quantification of cfDNA and found that peak cfDNA levels were significantly higher in patients compared with controls (48). Cui et al explored a bDNA-based Alu assay and reported that patients with acute coronary syndrome (ACS) showed a significant increase in plasma cfDNA concentrations compared with the controls. Moreover, they found positive correlations between cfDNA and Gensini scoring and Global Registry of Acute Coronary Events (GRACE) scoring in ACS (45).

In this study, we applied Alu-based real-time PCR to detect cfDNA in plasma samples from patients with MI. We found that the 5 different Alu PCR products were much higher in the MI group than in the normal individuals, which was consistent with the results of previous studies $(31,42)$. We evaluated the prognostic ability of Alu-based real-time PCR for discriminating patients with $\mathrm{MI}$ from healthy controls, and ROC curves of cTnI, CK, CK-MB, LDH, Alu1, Alu2, Alu3, Alu4, Alu5 and Alu were drawn. The AUC for Alu1, Alu2, Alu3, Alu4, Alu5 and Alu was 0.887, 0.758, 0.857, 0.940, 0.968 and 0.933 , respectively. In our study, Alu4, Alu5 and Alu showed better sensitivity and specificity for the diagnosis of patients with MI compared with CTnI, CK, CKMB and LDH. In particular, Alu5 displayed the best prognostic ability.

In conclusion, we developed a novel real-time PCR method based on Alu reduplicative sequences and proved that this is a reliable, accurate and sensitive method for the quantitative detection of cfDNA. This method may prove useful in studying cfDNA regulation in a variety of human pathological conditions.

\section{Acknowledgements}

This study was supported by the Shanghai Natural Scientific Foundation (grant no. 12ZR1428200) and the Scientific research project supported by the Shanghai Municipal Commission of Health and Family Planning (grant no. 20134Y179) and the Science and Technology Research Project of Songjiang District of Shanghai (Research of Circulating DNA in plasma in acute myocardial infarction patients).

\section{References}

1. Jung K, Fleischlacker M and Rabien A: Cell-free DNA in the blood as a solid tumor biomarker-a critical appraisal of the literature. Clin Chim Acta 411: 1611-1624, 2010.

2. Boddy JL, Gal S, Malone PR, Harris AL and Wainscoat JS: Prospective study of quantitation of plasma DNA levels in the diagnosis of malignant versus benign prostate disease. Clin Cancer Res 11: 1394-1399, 2005.

3. Gautschi O, Bigosch C, Huegli B, et al: Circulating deoxyribonucleic acid as prognostic marker in non-small-cell lung cancer patients undergoing chemotherapy. J Clin Oncol 22: 4157-4164, 2004.
4. Jahr S, Hentze H, Englisch S, et al: DNA fragments in the blood plasma of cancer patients: quantitations and evidence for their origin from apoptotic and necrotic cells. Cancer Res 61: 1659-1665, 2001

5. Goebel G, Zitt M and Müller HM: Circulating nucleic acids in plasma or serum (CNAPS) as prognostic and predictive markers in patients with solid neoplasias. Dis Markers 21: 105-120, 2005.

6. Ellinger J, Wittkamp V, Albers P, et al: Cell-free circulating DNA: diagnostic value in patients with testicular germ cell cancer. J Urol 181: 363-371, 2009.

7. Schwarzenbach H, Stoehlmacher J, Pantel K and Goekkurt E: Detection and monitoring of cell-free DNA in blood of patients with colorectal cancer. Ann NY Acad Sci 1137: 190-196, 2008.

8. Zachariah RR, Schmid S, Buerki N, et al: Levels of circulating cell-free nuclear and mitochondrial DNA in benign and malignant ovarian tumors. Obstet Gynecol 112: 843-850, 2008.

9. Zheng Z, Luo Y and McMaster GK: Sensitive and quantitative measurement of gene expression directly from a small amount of whole blood. Clin Chem 52: 1294-1302, 2006.

10. Hwu HR, Roberts JW, Davidson EH and Britten RJ: Insertion and/or deletion of many repeated DNA sequences in human and higher ape evolution. Proc Natl Acad Sci USA 83: 3875-3879, 1986.

11. Lander ES, Linton LM, Birren B, et al: Initial sequencing and analysis of the human genome. Nature 409: 860-921, 2001.

12. Mandel $P$ and Metais P: Les acides nucleiques du plasma sanguin chez l'homme. C R Seances Soc Biol Fil 142: 241-243, 1948.

13. Gormally E, Caboux E, Vineis P and Hainaut P: Circulating free DNA in plasma or serum as biomarker of carcinogenesis: practical aspects and biological significance. Mutat Res 635: 105-117, 2007.

14. Lam NY, Rainer TH, Chan LY, Joynt GM and Lo YM: Time course of early and late changes in plasma DNA in trauma patients. Clin Chem 49: 1286-1291, 2003.

15. Zhong XY, Laivuori H, Livingston JC, et al: Elevation of both maternal and fetal extracellular circulating deoxyribonucleic acid concentrations in the plasma of pregnant women with preeclampsia. Am J Obstet Gynecol 184: 414-419, 2001.

16. Galeazzi M, Morozzi G, Piccini M, et al: Dosage and characterization of circulating DNA: present usage and possible applications in systemic autoimmune disorders. Autoimmun Rev 2: 50-55, 2003.

17. Jylhävä J, Jylhä M, Lehtimäki T, Hervonen A and Hurme M: Circulating cell-free DNA is associated with mortality and inflammatory markers in nonagenarians: the Vitality 90+ Study. Exp Gerontol 47: 372-378, 2012.

18. Jylhävä J J, Nevalainen T, Marttila S, et al: Characterization of the role of distinct plasma cell-free DNA species in ageassociated inflammation and frailty. Ageing Cell 12: 388-397, 2013.

19. Nicolaides KH, Wright D, Poon LC, Syngelaki A and Gil MM: First-trimester contingent screening for trisomy 21 by biomarkers and maternal blood cell-free DNA testing. Ultrasound Obstet Gynecol 42: 41-50, 2013.

20. Johnson J, Pastuck M, Metcalf A, et al: First-trimester Down syndrome screening using additional serum markers with and without nuchal translucency and cell-free DNA. Prenatal Diagnosis 33: 1-6, 2013.

21. Moreira VG, Prieto B, Rodríguez JS and Alvarez FV: Usefulness of cell-free plasma DNA, procalcitonin and C-reactive protein as markers of infection in febrile patients Ann Clin Biochem 47: 253-258, 2010.

22. Gao YJ, He YJ, Yang ZL, et al: Increased integrity of circulating cell-free DNA in plasma of patients with acute leukemia. Clin Chem Lab Med 48: 1651-1656, 2010.

23. Saukkonen K1, Lakkisto P, Pettilä V, Varpula M, Karlsson S, Ruokonen E and Pulkki K; Finnsepsis Study Group: Cell-free plasma DNA as a oredictor of outcome in severe sepsis and septic shock. Clin Chem 54: 1000-1007, 2008.

24. Rhodes A, Wort SJ, Thomas H, Collinson P and Bennett ED: Plasma DNA concentration as a predictor of mortality and sepsis in critically ill patients. Crit Care 10: R60, 2006.

25. Huttunen R, Kuparinen T, Jylhävä J, et al: Fatal outcome in bacteremia is characterized by high plasma cell free DNA concentration and apoptotic DNA fragmentation : a prospective cohort study. PLoS One 6: e21700, 2011.

26. Mosca M, Giuliano T, Cuomo G, et al: Cell-free DNA in the plasma of patients with systemic sclerosis. Clin Rheumatol 28: $1437-1440,2009$. 
27. Zanetti-Dällenbach RA, Schmid S, Wight E, et al: Levels of circulating cell-free serum DNA in benign and malignant breast lesions. Int J Biol Markers 22: 95-99, 2007.

28. Zhong XY, Ladewig A, Schmid S, et al: Elevated level of cell-free plasma DNA is associated with breast cancer. Arch Gynecol Obstet 276: 327-331, 2007.

29. Chen JA, Meister S, Urbonaviciute V, et al: Sensitive detection of plasma/serum DNA in patients with systemic lupus erythematosus. Autoimmunity 40: 307-310, 2007.

30. Zhong XY, von Mühlenen I, Li Y, et al: Increased concentrations of antibody-bound circulatory cell-free DNA in rheumatoid arthritis. Clin Chem 53: 1609-1614, 2007.

31. Chang CP, Chia RH, Wu TL, et al: Elevated cell-free serum DNA detected in patients with myocardial infarction. Clin Chim Acta 327: 95-101, 2003.

32. Beck J, Urnovitz HB, Riggert J, et al: Profile of the circulating DNA in apparently healthy individuals. Clin Chem 55: 730-738 2009.

33. Shukla D, Kale AD, Hallikerimath S, Yerramalla V and Subbiah V: Can quantifying free-circulating DNA be a diagnostic and prognostic marker in oral epithelial dysplasia and oral squamous cell carcinoma? J Oral Maxillofac Surg 71: 414-418, 2013.

34. Cepika AM, Soldo Jureša D, Morović Vergles J, et al: Decrease in circulating DNA, IL-10 and BAFF levels in newly-diagnosed SLE patients after corticosteroid and chloroquine treatment. Cell Immunol 276: 196-203, 2012

35. Catarino R, Coelho A, Araújo A, et al: Circulating DNA: diagnostic tool and predictive marker for overall survival of NSCLC patients. PLoS One 7: e38559, 2012.

36. Szpechcinski A, Chorostowska-Wynimko J, Kupis W, et al: Quantitative analysis of free-circulating DNA in plasma of patients with resectable NSCLC. Expert Opin Biol Ther 12 (Suppl 1): 3-9, 2012.

37. Huang Z, Hua D, Hu Y, et al: Quantitation of plasma circulating DNA using quantitative PCR for the detection of hepatocellular carcinoma. Pathol Oncol Res 18: 271-276, 2012.

38. Liggett T, Melnikov A, Yi QL, et al: Differential methylation of cell-free circulating DNA among patients with pancreatic cancer versus chronic pancreatitis. Cancer 116: 1674-1680, 2010.
39. Horlitz M, Lucas A and Sprenger-Haussels M: Optimized quantification of fragmented, free circulating DNA in human blood plasma using a calibrated duplex real-time PCR. PLoS One 4: e7207, 2009.

40. Szpechcinski A, Struniawska R, Zaleska J, et al: Evaluation of fluorescence-based methods for total vs. amplifiable DNA quantification in plasma of lung cancer patients. J Physiol Pharmacol 59 (Suppl 6): 675-681, 2008.

41. Sang F and Ren J: Comparisons between capillary zone electrophoresis and real-time PCR for quantification of circulating DNA levels in human sera. J Chromatogr B Analyt Technol Biomed Life Sci 838: 122-128, 2006.

42. Jing RR, Wang HM, Cui M, et al: A sensitive method to quantify human cell-free circulating DNA in blood: relevance to myocardial infarction screening. Clin Biochem 44: 1074-1079, 2011.

43. Yeh RW, Sidney S, Chandra M, et al: Population trends in the incidence and outcomes of acute myocardial infarction. N Engl J Med 362: 2155-2165, 2010.

44. Thygesen K, Alpert JS and White HD; Joint ESC/ACCF/ AHA/WHF Task Force for the Redefinition of Myocardial Infarction: Universal definition of myocardial infarction. J Am Coll Cardiol 50: 2173-2195, 2007.

45. Cui M, Fan M, Jing R, et al: Cell-free circulating DNA: a new biomarker for the acute coronary syndrome. Cardiology 124 : 76-84, 2013.

46. Destouni A, Vrettou C, Antonatos D, et al: Cell-free DNA levels in acute myocardial infarction patients during hospitalization. Acta Cardiol 64: 51-57, 2009.

47. Antonatos D, Patsilinakos S, Spanodimos S, et al: Cell-free DNA levels as a prognostic marker in acute myocardial infarction. Ann NY Acad Sci 1075: 278-281, 2006.

48. Shimony A, Zahger D, Gilutz H, et al: Cell free DNA detected by a novel method in acute ST-elevation myocardial infarction patients. Acute Card Care 12: 109-111, 2010. 